\title{
STRATEGY AND TACTICS OF NANOINDUSTRY DEVELOPMENT IN THE RUSSIAN FEDERATION
}

The paper grounds the transition from the theories of technological modes and macrogenerations to the theory of socioeconomic modes and megagenerations. Different approaches to the understanding of nanoeconomy, especially nanoindustrialization in Russia are reviewed. The essence of metapproductional function as a function of nanomanufacturing is described, the structure of basic levels and meso-levels of nanotechnology economy is proposed and related forms of research of socioeconomic problems of the national nanotechnology are revealed.

Keywords: nanoindustry, socioeconomic mode, nanorelevant enterprizes, function of nanoproduction.

The processes of nanoindustrialization in the beginning of the XXI century have become objects of state regulation in a global scale. To 2008, 55 of 191 world countries (about 29\%) elaborated and approved their own strategies of nanotechnologies development and nanoindustry formation. This process quickly progressed: 2000-2001 — the USA, the European Union, China, South Korea, Singapore... 2002-2003 — Israel, India, Japan, Taiwan... 2007 - Russia...

Strategic management of the nanoindustrialization is caused by the beginning of a new $\mathrm{N}$. Kondrat'ev cycle in 2004-2005 and formation of the VI technological mode in the global economy system. As the integration of long waves creation models in manufacturing and business infrastructure (M. Hirooka) shows, the formation of the VI technological mode started with creation of a "bundle of combined technologies" before the current global economic recession and is not closely related to it. But the crisis became a fillip for modernization and neoindustrialization in form of nanoindustriali- zation that «launched» the mechanism of innovational renewal (J. A. Schumpeter) in the scale of a global economic system.

The state in terms of national-oligarchical capitalism acts as a locomotive, a driving force of nanoindustry development, creating political, scientific and investment capacity, forming transactional field, creating a platform for transnational corporations, large enterprises, middle-sized venture companies, using, integrating or liquidating small competitors.

The NBIC-convergence theory (M. Roco, W. Bainbridge, K. Borner) does not exhaust the content of the не исчерпывает содержание VI technological mode, ignoring the elaboration of adequate socioeconomic mode components formation. This theory is incorrectly interpreted in Russia (V. Pride, D. Medvedev). All technologies are in need for corresponding community relations and are changing them. It is strategically important to separate and highlight transformational and transactional components (conditions, resources, factors 
and products) of the nanoindustrialization in order to create a «road map» of socioeconomic mode development, which is adequate to understanding the essence of the nanolevel and nanoindustry of the global economic system.

For elaborating a strategy of nanoindustry development, a transition from the theories of technological modes and macrogenerations (D. L'vov, S. Glaz'ev, V. Maevskiy, V. Ivanter, B. Kuzyk, Yu. Yakovets et. al.) to the theory of socioeconomic modes and megagenerations while synthesizing the theories of cycles by Kondratiev and communityeconomy formations (K. Marx) is productive.

Nanoindustrialization has a global, level-sensitive, above-branch character. This is the process and the form of enlargement of the global economic system, establishment of the new boundaries of social life. Its result is the nanoindustry - an institutionally specified, large-scale organized, mass production of standardized goods with nanocharacteristics.

Megageneration of the nanoindustry forms its structure and infrastructure on the local, regional, national and global levels (enterprises and markets, flows and channels, knots and centres, poles and zones). The process of global and national, regional and local nanoindustry markets has started. The prognosticative volume of the global nanoindustry market until 1015 - 1-3 trillion USD, that will require up to additional 2.0 million workplaces and 5.0 million workers employed in "associated groups". A pinpoint for the Russian Federation: level of nanoproduction industry - 30 billion USD per year, share on the global market $-1-4 \%$, and workers employed in "associated groups" - 0,15 and 0,3 million people.

Nanoindustrialization means not only nanoindustry economy development with relevant enterprises and their relations, but also nanoeconomy as

a special part of the subject field of the economy theory. Utilitarian, behaviourist, institutional and ecogenetic approaches to the understanding of the nanoeconomy have revealed themselves (see Fig. 1).

Nanoeconomy is changing the composition of economic agents, their relationships to resources and factors of production, creating new connections and forms of business, labour functions, operations and actions of employees, ways of manufacture management and regulation, distribution, exchange and consumption. Forms of social division and cooperation of labour, production and management from the individual workplace to the world economy are changing. Nanoindustrialization causes a change in the social content and form, quality and quantity, level and lifestyle of people at all levels of the global economic system. Creation of nanoeconomy and nanoindustry theory (K. Allow, G. Kleiner, O. Inshakov et. al.) significantly corrects theories of postindustrial and posteconomical societies (D. Bell, V. Inozemtsev) and extends the content of the evolutional economics.

In the Russian Federation only in 2007 the Presidential initiative «Strategy of nanoindustry development» was approved. Furthermore it was reflected in federal, departmental and cross-sector target programs but not appeared in sectoral (on energy, transport, building etc.) and regional target programs. In 2009 only in 23 subjects of the Russian Federation $(27.7 \%)$ there were strategic elaboration lay-outs agreements and approved programs of nanoindustry development.

For the formation of the structure and infrastructure of the national nanoindustry in terms of National nanotechnological network, a special institute of development was created - State Corporation «Russian Corporation of Nanotechnologies»

\begin{tabular}{|c|}
\hline $\begin{array}{c}\text { Behaviourist } \\
\text { conception }\end{array}$ \\
$\begin{array}{l}\text { Evolutional } \\
\text { conception }\end{array}$ \\
\hline
\end{tabular}

Nanoeconomy - the whole system of economic relations associated with the development of nanotechnology and nanoindustry, regardless of their size (from megato microsystems)

$$
\text { Institutional conception }
$$

Nanoeconomy economy of interaction of individuals (natural persons) in microeconomy systems
Nanoeconomy - sphere of economic relations connected with the behaviour of individuals (natural persons) and possibilities of its regulation in macro- and microeconomy systems
Nanoeconomy - special level and sphere of economy, system of relations determined by the combinations of endogenous production factors in the actions of its actors

Fig. 1. Basic conceptions of nanoeconomy in the modern economics theory 
(RUSNANO) with the initial capital of 130 million rubles, which is now implementing 94 projects in 30 regions of the country (of overall 1758 submissions). Active assets of Russia in RUSNANO - 4.5 billion USD, state funded loans -6.2 billion USD. Summary investments reached 10.1 billion USD (corporation - 40.6\%, business - 59.4\%). Equity participation of business in projects is $>50 \%$, investment horizon is 10 years. Leading research organization, the coordinator of activities in the field of nanotechnology and the creation of the National nanotechnology network is the research center «Kurchatov Institute». The main task is putting Russia into the top league of global nanoindustrialization participants until 2015 by the late start and large unrealized potential.

Modern policy of strategic nanoindustry development reflects the initiation of Russia into the first phase of the VI technological mode (2004-2015). This policy has the mobilization character, implementing a selective approach, motivating private businesses, reducing its risks and ensuring its growth. RUSNANO helps to improve the competitive environment, develops «grafted branches» technologies of product foresight and «road maps» of cluster development, standardization and certification, safety in the nanotechnological industry, personnel training and promotion of nanotechnologies.

The strategy of nanoindustrialization in Russia is weakly institutionalized and socialized. In the approved documents, priorities and imperatives, horizons and orientations, methods and tools for achieving the goal are not set meaningfully enough. The contradictions of the process, its negative externalities and internals, «boomerangs of nanoindustrialization» in the environmental and economic, political, legal and socio-cultural spheres are not taken into account.

Nanoindustrialization is very non-uniform in space and time, «focal» form of components and products of nanotechnology growth dominates. Within the boundaries of the Federation, the center of hyperactivity and concentration (Moscow), the poles of high activity (6) and complete passivity (23), the promotion zone (Central Federal District, Northwestern Federal District, Volga Federal District) and gaps of nanoindustrialization process (Far East Federal District, North Caucasian Federal District, Southern Federal District) have formed. Targeted programs, plans or projects are being implemented by 585 organizations that are relevant to the nanoindustry. In the Central Federal District
$53.3 \%$ of organizations are concentrated, and in Far East Federal District and North Caucasian Federal District - 1.7\%. In the economic space of Russia this creates a «pebble-leather effect», increases the threat of its desolation and alienation in the neighborhood. Five standards for nanotechnology in higher vocational education are created; these provide training in 35 universities of Russia. There are no second level of education and workers education standards.

Analysis of the Development strategy of nanotechnology in Russia proves the need for a substantial complement of its philosophical, methodological and theoretical foundations for the effective implementation on the subsequent stages, the prevention of complex socio-economic conflicts and crises. This applies both to its paradigm, the vision and mission, as well as software and tactical control mechanisms.

For the successful implementation of the strategy, a fairly complete, accurate and accessible information provision for monitoring the development of nanoindustry is required. There is a need to develop official statistics of the main component of the nanoindustry - nanorelevant enterprises and companies - according to their size and circulation of capital, the number of socio-insured workers, areas, sectors and activities, regions and cities, volume, range and structure of output, revenue and profitability trends and development rates. This will allow regulating the dynamics of nanotechnology formation in various aspects and scopes.

Studies related to the evolution of socio-economic processes, occurring effects, structural changes and contradictions, forms and norms of activity and behavior, perspectives and consequences, risks and threats of nanoindustry development are not being made in proper scale and not funded at the necessary volume. Economics, sociology, law and culture are the «broken off branches» of the strategic objectives tree. The global nanoindustrialization leaders have already faced such a backlog and demand for strategic «completion» (the USA, the European Union and others).

The society lags understanding these issues. The number of Russian documents containing the terms with the component «nano» in the Google engine search results on November 17, 2010: nanotechnology -1.72 million; nanoindustry -151000 ; nanoeconomy - 1430; nanophilosophy - 1040; nanosociology -28 ; nanojurisprudence -6 ; nanoculturology -1 . 


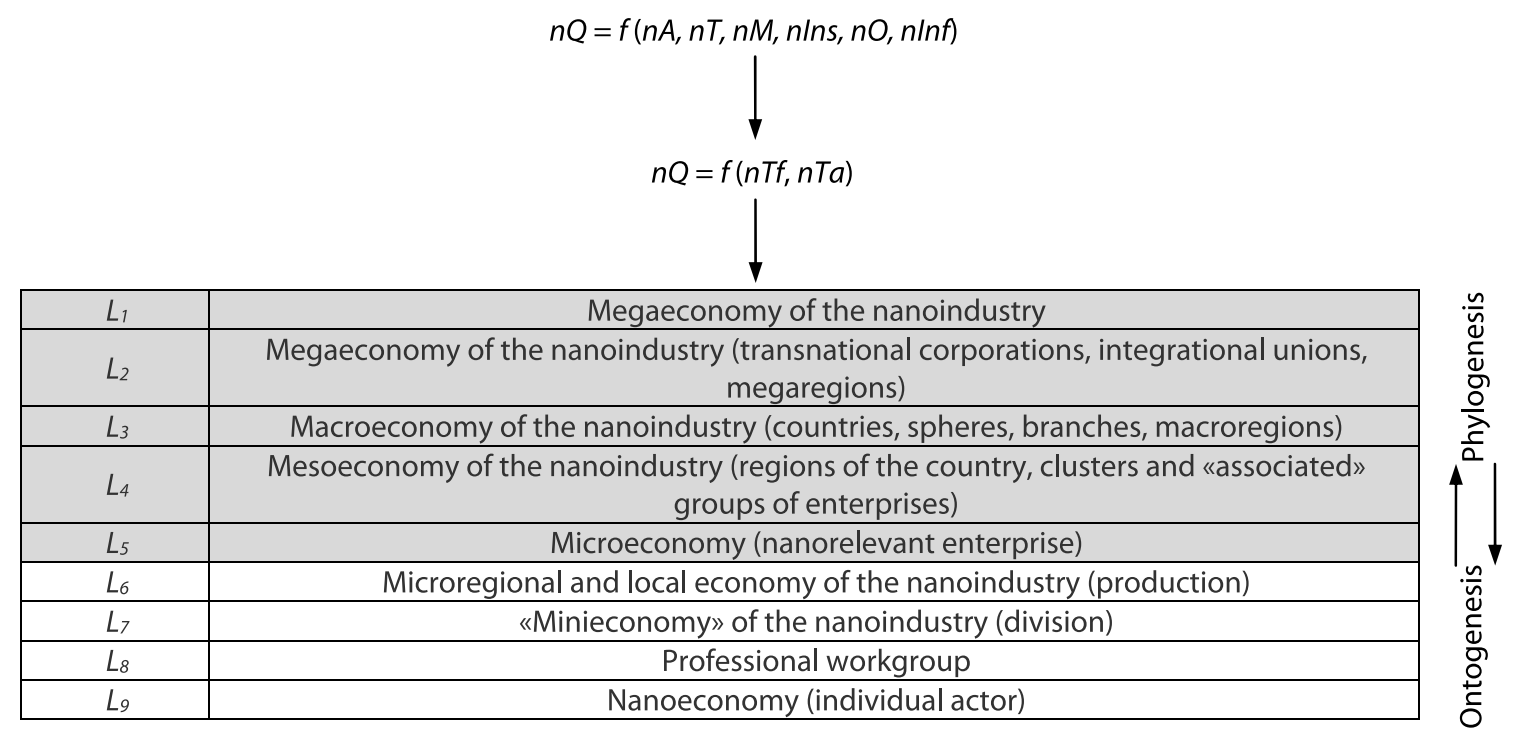

Fig. 2. The structure of basic $\left(L_{1^{\prime}} L_{3^{\prime}} L_{5^{\prime}} L_{7^{\prime}} L_{9}\right)$ and mesolevels of the nanoindustrial economy

Meaningful development of nanoindustrialization strategy in Russia can be supported by the use of models such as «Nature-Man-Society», metaproduction function $(Q)$ and multilevel (from $L_{1}$-mega to $L_{9}$-nano (Fig. 2)) structure of the global economy (O. Inshakov). This would widen the scientific basis of this strategy in terms of aspects, resources, factors, products, revenues, investments and capitals in accordance with the imperatives and priorities of the Russian Federation.

Metaproduction function as the function of nanoproduction:

$$
Q=f(A, T, M, \text { Ins, } O, \text { Inf }),
$$

where $Q$ is the made product; endogenous variables - production factors: $A$ - human; $T$ - technical; $M$ - material; Ins - institutional; $O$ - organizational; Inf - informational. $A, T, M$ - transformational factors - Tf; Ins, $O$, Inf - transactional factors $-T a$.

To ensure rapid response to changes of parameters of the strategic trajectory of nanoindustrialization in Russia, there is a need to develop systems to monitor this process with the appropriate centers of responsibility, relevant indicators and effective modes.

The nanoindustrialization tactics in the regions shows the paucity of the methods and instruments for its regulation. There is a necessity for differentiation of the diversity of sources, channels, tools and methods to regulate nanotechnology for their effective combinations that are appropriate to different levels, scales and forms of organization. Promising is the modeling of continuous tactical management and sustainable development of nanotechnology-based theory of the economic mechanism (L. Abalkin, N. Petrakov, S. Shatalin).

The most important direction is becoming the development of economic and genetic analysis of human activity on the nanoscale (operations, activities, methods, movements) that will develop tactical ways to improve its efficiency in the future. This will serve as the basis for developing advanced technologies for accounting, analysis, management and marketing. Creating social and economic technologies to improve the quality of human life is based on understanding the role and place of the nanoscale in the structure of the economy and the society — the future of science.

In the Plan for basic research of the Russian Academy of Sciences for years 2006-2025, in Section 8 "Social sciences" in the part before 2010, the term "nano" does not appear at all, and in part related to years 2011-2025, - 1 time in Section 8.2 - as "Nanoeconomy". Apparently, there is a need for correction of the existing plans and creation of new forms of fundamental research organization on socio-economic problems of the national nanotechnology institutes for implementation in the Department of Social Sciences of the Russian Academy of Sciences.

Hopes for a strong technological breakthrough and economic modernization of Russia in the conditions of formation and growth of VI technological mode suggest the organization of large-scale studies of the evolution, strategy and technology development of social relations that are adequate to the specifics of the new socio-economic structure. 


\section{Information about the author}

Inshakov Oleg Vasil'evich (Volgograd) - Doctor of Economics, Professor, Rector of the State Educational Institution of Higher Professional Education «Volgogorad State University» (400062, Volgograd, Universitetsky Pr. 100, e-mail: rector@volsu.ru) 